\title{
SPECIFIC FEATURES OF AUTOMOBILE BRAKE LININGS
}

\author{
VLADIMIR HLAVŇA' \\ University of Žilina
}

\section{Summary}

Braking of road vehicles can be characterized as an active - either wanted or unwanted reduction of the force necessary for maintaining the required speed, decreasing the speed, stopping or keeping the vehicle at a standstill. During braking the vehicle loses the acquired motion energy which is most frequently transformed (in case of wanted braking) in the brake system of the vehicle into useless heat released to the environment. Brake force can be defined as the force acting against the motion of a vehicle which is, in case of wanted braking, produced by the vehicle braking system. In case of wanted braking we usually begin with the equilibrium equation of vehicle forces. The paper deals with objective findings and assessment of possible causes leading to the braking system failure paying special attention to the brake lining. The user can approach the brake lining failure from two points of view: being aware or unaware of it. Laboratory tests can be used to objectively assess characteristics of brake linings. Both operational and laboratory test are performed to detect characteristics of brake lining materials. Apart from theoretical considerations, the paper also contains results of experiments performed with different brake lining materials used for trucks and passenger automobiles.

Keywords: braking, brake linings, laboratory testing

\section{Introduction}

Braking can be characterized as an active (wanted or unwanted) reduction of the force needed:

- to stop the vehicle,

- to decelerate the speed,

- to maintain the required speed when driving downhill,

- to keep the vehicle at a standstill.

During braking the vehicle loses the acquired motion energy which is most frequently transformed (in case of wanted braking) in the brake system of the vehicle into useless heat released to the environment. There are some exceptions:

- when a motor brake is used (the combustion engine works in the motor brake regime),

- when a dynamic brake is engaged (retarder),

\footnotetext{
1 University of Žilina, Faculty of Mechanical Engineering, 1 Univerzitna Street, 01026 Žilina, Slovak Republic, e-mail: vladimir.hlavna@efstroj.uniza.sk, ph. +421 415132670
} 
- when deformation or friction work (unwanted braking) occurs, e.g. in collisions, technical failure of some vehicle parts - most frequently a failure of the vehicle moving system, ...

- other causes either wanted or unwanted.

An objective of the paper is to point out one of the possible ways leading to an objective finding and assessment of a cause leading to the brake system failure; more precisely the failure of the brake lining, which can result into an accident. The user can approach the mentioned failure from two angles: he can either be aware or unaware of it. However, the car accident expert has to objectively investigate the cause leading to the brake system failure, i. e. to investigate also characteristics of the brake lining and to express his judgment whether the lining meets the necessary requirements.

The structure of the paper is identical with the structure of the investigation of a concrete bus accident with the focus on its final phase - laboratory test of the brake lining.

\section{A Note on the Theory of Braking}

Brake force can be defined as the force acting against the motion of a vehicle which is, in case of wanted braking, produced by the vehicle braking system. In case of unwanted braking the force can be produced by other, usually external factors, e.g. driving failure, collision, etc.

In case of wanted braking we usually begin with the equilibrium equation of the vehicle forces. In case of wanted braking in critical situations the requirement to achieve the minimum stopping distance is prioritized (i.e. a full use of the possible maximum coefficient of cohesion between the road and the drive avoiding blocking any wheel). Then, the mentioned equilibrium equation of forces for the vehicle can have, for example, the following form:

$$
\begin{gathered}
\operatorname{sign} M_{m} \cdot i_{c} \cdot \eta_{m} \cdot r^{-1}+f \cdot G \cdot \cos \alpha+\operatorname{sign} G \cdot \sin \alpha+0.5 \cdot \rho \cdot c_{x} \cdot S \cdot v^{2}+ \\
+m \cdot a \cdot\left(1+\left(I_{m} \cdot{i_{c}}^{2}+I_{p} \cdot i_{r}{ }^{2}+I_{k}\right) \cdot\left(m \cdot r^{2}\right)^{-1}\right)=0,
\end{gathered}
$$

where the following members express: force in the wheels induced by driving or braking moment of the engine $M_{m}\left(i_{c}\right.$ - total transmission ratio, $\eta_{m}$ - mechanical efficiency of transmission, $r$ - dynamic radius of driving wheels), rolling friction ( $\mathrm{f}$ - rolling friction coefficient, $\mathrm{G}$ - vehicle mass, $\alpha$ - slope angle of a plate, influence of the plate slope, aerodynamic resistance ( $\rho$ - air density, $c_{x}$ - air resistance coefficient, $S$ - vehicle front end part, $v$ - velocity), inertia resistance considering the influence of rotating masses ( $\mathrm{m}$ vehicle weight, a - acceleration, $\mathrm{I}_{\mathrm{m}}$ - mass moment of inertia of parts rotating at crankshaft angular velocity, $I_{p}$ - mass moment of inertia of parts rotating at angular velocity behind the gearbox, $\mathrm{i}_{\mathrm{r}}$ - transmission ratio of drive axle, $\mathrm{I}_{\mathrm{k}}$ - mass moment of inertia of parts rotating at angular velocity of wheels). The problem is usually more complicated in case of unwanted braking, i.e. braking induced by a traffic situation. To analyze such braking is more complicated and it is better to split it into separate phases. The phases are 
characterized by at least partly unchangeable conditions with one prevailing, dominant feature, for example:

- "classical braking",

- wedge collision,

- sliding collision,

- braking with increased friction,

- braking with the vehicle rotation.

For the analytical solution of such braking the fundamental laws of mechanics are generally applied, namely:

- conservation of energy,

- conservation of motion,

- conservation of momentum.

When solving unwanted braking analytically, it is possible to begin with Lagrange equation of second kind

$$
\frac{d}{d t}\left(\frac{\partial E_{k}}{\partial \dot{\varphi}_{i}}\right)-\frac{\partial E_{k}}{\partial \varphi_{i}}+\frac{\partial E_{p}}{\partial \varphi_{i}}=F_{i}
$$

in which: $E_{k}$ is kinetic energy of the system, the expression between parentheses is a common impulse, $\mathrm{E}_{\mathrm{p}}$ is potential energy of the system, $\varphi_{\mathrm{i}}$ is $\mathrm{i}$-th common coordinate, $\dot{\varphi}_{i}$ is $i$-th common velocity, $F_{i}$ is common force of $i$-th mass which needs no dimensions of force similarly as the common coordinate needs no dimensions of length. But, at the same time, the following relation must hold

$$
F_{i}=\frac{\partial A_{i}}{\partial \varphi_{i}}
$$

in which $\mathrm{A}_{\mathrm{i}}$ is work of $\mathrm{i}$-th mass.

It is not a problem to determine kinetic energy of the system (vehicle) for the investigated motion. Potential energy of the system (vehicle) changes if, during unwanted braking (collision), the vertical coordinate of the centre of gravity changes.

The situation changes if during unwanted braking the mass of the system (vehicle) changes due to separation of marginal masses. Supposing mass mj depends on time only, radius vectors of points of the body expressed by general coordinates are ${ }_{j}=r_{j}\left(\varphi_{1} \ldots . \varphi_{n}\right.$ and denoting

$$
G_{i}=\sum_{j} \frac{d m_{j}}{d t} u_{j} \frac{\partial r_{j}}{\partial \varphi_{i}}
$$

Lagrange equation of second kind will have a form

$$
\frac{d}{d t}\left(\frac{\partial E_{k}}{\partial \dot{\varphi}_{i}}\right)-\frac{\partial E_{k}}{\partial \varphi_{i}}+\frac{\partial E_{p}}{\partial \varphi_{i}}=F_{i}+G_{i} .
$$


If it is not possible to solve the system of equations, e.g. due to a greater number of unknown quantities than the number of equations is, then nontraditional procedures resulting from practical experience can be implemented. In forensic engineering for example, methods using Energy Equivalent Speed (EES) or Equivalent Barrier Speed (EBS) are implemented for analysis of road accidents. By means of EES deformation energy $\mathrm{E}_{\text {def }}$ related to the change of velocity $\mathrm{v}_{\text {pred }}-\mathrm{v}_{\mathrm{po}}$ is expressed by the relation

$$
E_{d e f}=0.5 m \cdot\left(E E S^{2}\right) \text { or } 0.5 m \cdot\left(v_{p r e d}^{2}-v_{p o}^{2}\right)=0.5 m \cdot\left(E E S^{2}\right) \text {. }
$$

It is necessary to point out to the difference between the change in the velocity $\Delta \mathrm{v}=\mathrm{v}_{\text {pred }}-\mathrm{v}_{\mathrm{po}}$ and EES whose definition is given by relation (6), i.e. $E E S=\left(v_{\text {pred }}^{2}-v_{p o}^{2}\right)^{0.5}$ It is such speed which corresponds to the consumed deformation energy. EES is then determined either by guessing (comparison of deformations at a "crash" test with a real deformation) or by some of computation methods (they use, for example, data about EBS impact speed, about permanent deformation during barrier tests or ETS - Equivalent Test Speed). Thoroughly documented results of barrier tests enabled to acquire empirical equations providing high-accuracy calculation of EES (90 - 98\%) for different deformation depths and degrees of overlap crashes. When investigating car crashes, it is possible to use methods of forward or backward calculations. The method of forward calculation is iterative, based on solution of a set of equations so that the calculation result is compared with reality until the required accuracy is achieved. The method of backward calculation uses the final real situation (e.g. final position of vehicles after crash) to look for initial values of investigated quantities (speed, time, ...).

At present it is easier, more accurate and quicker to analyze braking either wanted or unwanted with computer equipment. There are packages of various programs which can be used for the mentioned purpose.

The above approaches were applied when theoretically dealing with parameters characterizing the braking of the bus in the critical situation. The gathered results initiated the requirement for investigation of the braking system with particular attention to the brake lining.

In the braking system important roles are played also by brake lining materials for brake shoes or disc brakes. That is the reason why legislation puts strict requirements on the material which have to be met. The requirements for brake lining materials are specified in the international standards ISO 6310, ISO 6312 or regulation R90.ECE. Regulation EHK 13 specifies requirements for new homologation of brakes and braking in wording of later regulations.

Characteristics of brake lining materials are assessed by following tests:

- operational, i.e. "vehicle tests",

- laboratory tests. 


\section{Vehicle testing of brake linings}

The brake efficiency is assessed during operational - vehicle testing in such a way that "within the range from the unladen weight up to the total vehicle weight the brakes have to always be able to stop the vehicle at least within the distance specified usually in tables or calculated according to given relations without exceeding the highest controlling power". The basic requirement for braking efficiency of operational and emergency braking is determined by a braking distance as a function of the initial speed. Braking efficiency is assessed by tests. They are specified for operational, emergency and parking braking for individual vehicle categories. Regulations specify concrete conditions to perform testing, e.g. for vehicle categories $\mathrm{M}$ and $\mathrm{N}$ there are more types of tests; basic test " 0 " specifies braking efficiency with interrupted/uninterrupted connection of the engine to the wheels. Test "l" assesses the decrease of efficiency of brakes heated by repeated braking in a specified mode.

The aim of operational testing is to verify braking distance, braking deceleration and braking time. During testing the corridor of vehicle path is outlined. The regulation specifies also other conditions of testing.

As it was impossible to assess the bus braking system by operational tests, laboratory tests were performed.

\section{Laboratory testing of vehicle brake linings}

Figs. 1 and 2 present modules of disc and shoe brakes of the flywheel braking test stand Fig. 3 (Setting scheme and a view of the braking test stand 1 - electromotor $(265 \mathrm{~kW}$, max. $\left.400 \mathrm{~kW}, 3.200 \mathrm{~min}^{-1}\right), 2$ - gearbox ( $\mathrm{i}=1.5$, or 1.72, or 4), 3 - clutch, 4 - flywheel $\left(400 \mathrm{~kg} \cdot \mathrm{m}^{2}\right.$ $=280+2 \times 5+3 \times 10+4 \times 15+20,5$ - flywheel $\left(600 \mathrm{~kg} \cdot \mathrm{m}^{2}\right), 6$ - flywheel $\left(900 \mathrm{~kg} \cdot \mathrm{m}^{2}\right)$, 7 - basic frame, 8 - module of disc brake) on which laboratory tests were performed.

The way in which the test is to be performed is usually specified by a standard according to the brake lining which is being used. Above all, the following characteristics are determined.
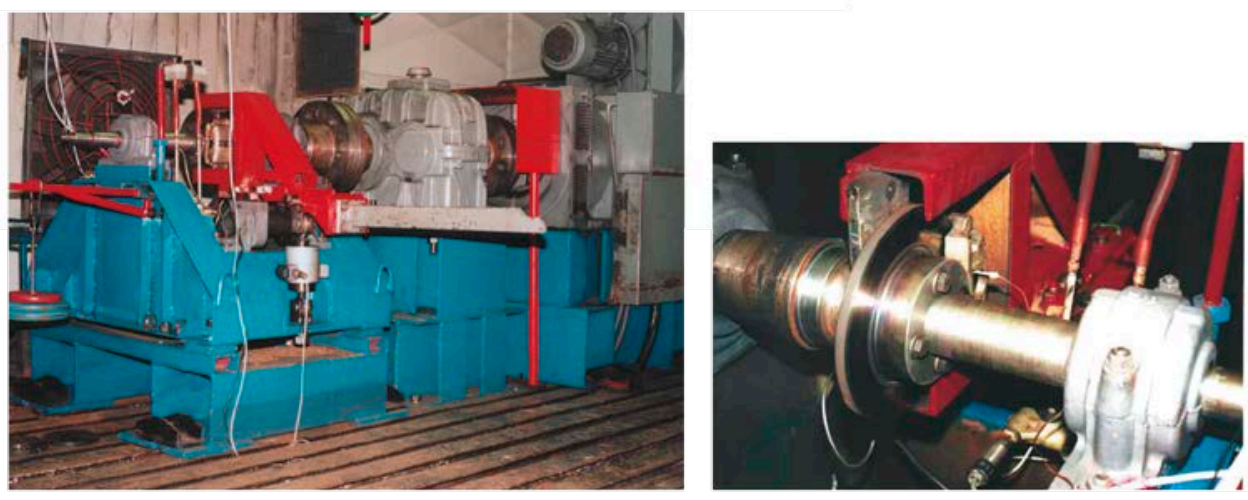

Fig.1. Disc brake - full view and detailed view 


\subsection{Mechanical characteristics}

From the mechanical characteristics of materials used for spare sets of brake linings we investigate shear strength and compressibility. The permitted minimum value of shear

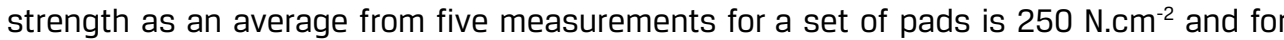
a set of shoes is $100 \mathrm{~N} . \mathrm{cm}^{-2}$. Fig. 4 presents the preparation for shear stress tests and brake pads samples ready for investigation of mechanical characteristics.
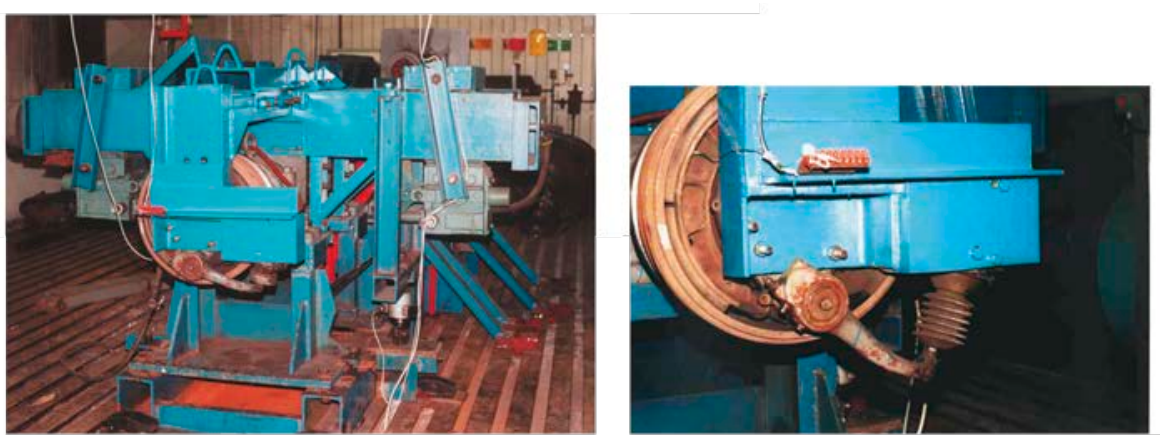

Fig.2. Brake shoe - full view and detailed view

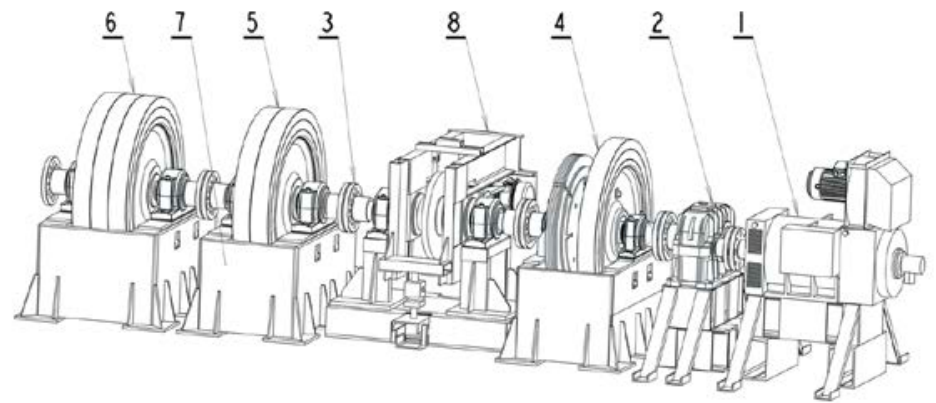

Fig.3. Flywheel braking test stand (1 - electromotor, 2 - gear box, 3 - clutch, 4, 5, 6 - flywheels, 7 - frame, 8 - exchange module for different types of brakes)
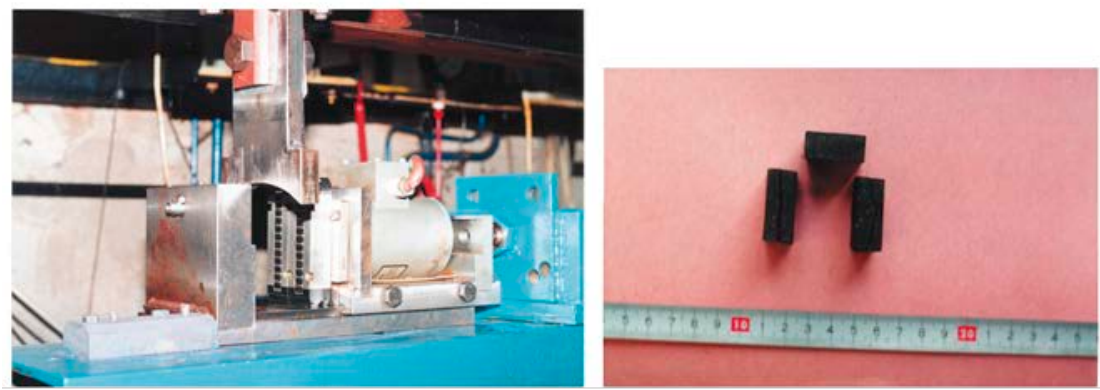

Fig.4. Preparation for shear stress tests and brake pads samples ready for investigation of mechanical characteristics 
When testing at ambient temperature the dependence of the loading force on time is recorded - Fig. 5. The velocity of loading is also defined. When a brake shoe or pad is tested, it is fixed onto the construction whose requirements have been specified.

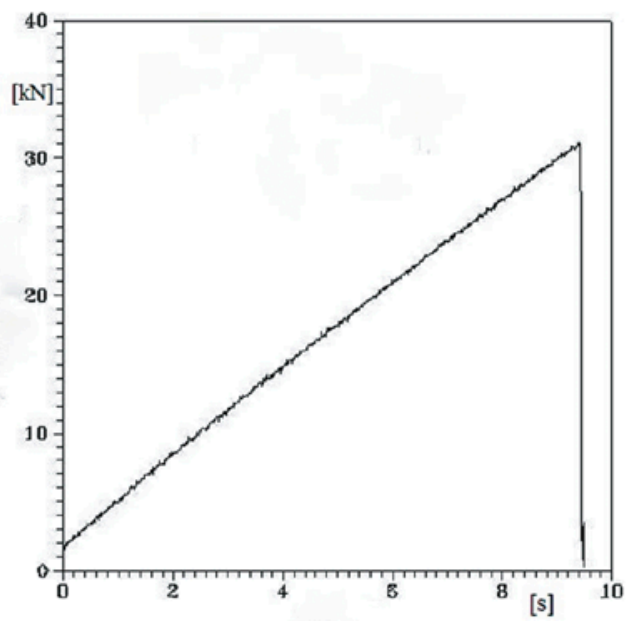

Fig.5. Result of shear stress test (time dependence of shear strength) [1].

We check the value of compressibility at ambient temperature and at the temperature increased to $200^{\circ} \mathrm{C}$ - a brake shoe and $400{ }^{\circ} \mathrm{C}$ - a brake pad. The permitted value of compressibility for ambient temperature is maximum $2 \%$, for the increased temperature $4 \%$ for shoes and $5 \%$ for pads. The compressibility test has to be carried out within the exactly specified procedure. The way in which it is investigated is also specified.

\subsection{Friction characteristics}

Friction characteristics are tested at the shaft (disc or drum) revolutions of $600 \pm 10 \mathrm{~min}^{-1}$ without loading. The revolutions must not be lower than $600 \mathrm{~min}^{-1}$ at full loading. The surface temperature of the brake is limited and the mean contact pressure on the brake lining surface is specified.

The test is carried out within exactly defined consequent cycles of braking which are separate for sets of brake shoes and separate for sets of brake pads. The friction characteristics are determined from the braking moment in those points of the test in which the braking agent is constant.

The evaluation is defined from the individual cycles of the test. For a set of the braking pads we assess:

- operational coefficient of friction whose value has to be within a range of $15 \%$ of the values declared,

- the highest coefficient of friction has to be equal to or less than the value declared,

- the lowest coefficient of friction has to be greater or equal to the value declared. 
For linings of the brake shoes we assess:

- mean braking moment whose value has to be within a range of $20 \%$ of the values declared,

- hot moment (the last braking moment from the cycle defined) whose value has to be equal to, or greater than the value declared.

\subsection{Characteristics of dynamic friction}

The characteristics of dynamic friction for a set of spare brake linings are assessed by comparing them with the characteristics of the original lining [2].

Sensitivity to speed is assessed in the diagram - Fig. 6, plotting the measured deceleration for pressure in the brake system corresponding to the deceleration of $5 \mathrm{~m}^{-s^{-2}}$ or $3 \mathrm{~m} . \mathrm{s}^{-2}$ respectively, depending on whether it is the front or rear axle brake, for braking from three speeds at the brake temperature to $100^{\circ} \mathrm{C}$. The initial speed for braking to stop is for the front (rear) axle brake $65 \mathrm{~km} \cdot \mathrm{h}^{-1}\left(45 \mathrm{~km} \cdot \mathrm{h}^{-1}\right)$ and $100 \mathrm{~km} \cdot \mathrm{h}^{-1}\left(65 \mathrm{~km} \cdot \mathrm{h}^{-1}\right)$. If the maximum speed of a vehicle is greater than $150 \mathrm{~km} \cdot \mathrm{h}^{-1}$, then the third braking is from the speed of $135 \mathrm{~km} \cdot \mathrm{h}^{-1}$ $\left(90 \mathrm{~km} . \mathrm{h}^{-1}\right)$. For vehicles with a maximum speed $150 \mathrm{~km} . \mathrm{h} .{ }^{\prime}$, the standard does not specify an initial speed for the third braking and, thus, it is done from the speed corresponding to $90 \%(60 \%)$ of the maximum speed of a vehicle.

For the approved set of spare brake linings, decelerations found at higher speeds have to be within a range of $15 \%$ of deviations of the measured decelerations for the lowest (65 km.h.', 45 km.h.') speed.

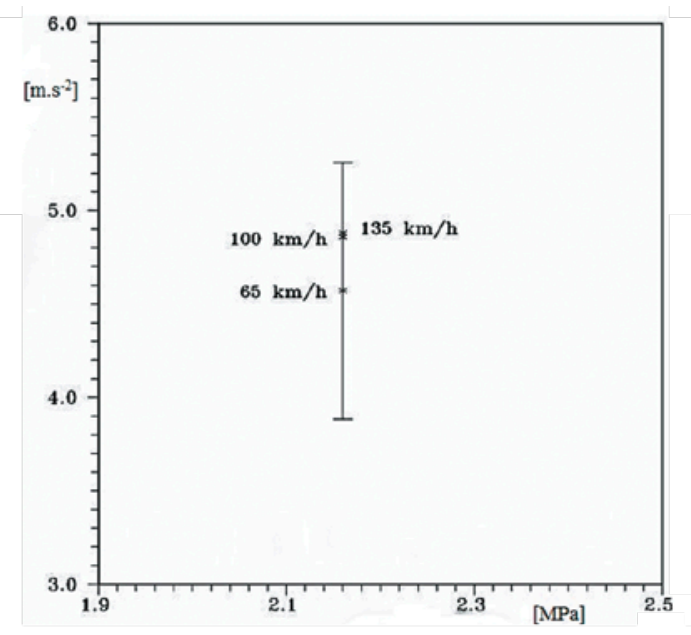

Fig.6. Assessment of sensitivity to speed (deceleration for the given pressure in the braking system) [1] 
A"cold effect" test is carried out in the following way: the standard specifies the initial speed and the brake temperature up to $100^{\circ} \mathrm{C}$; at the beginning of each of six brakings the brakes are applied gradually by means of an increased pressure in the system until the deceleration of $6 \mathrm{~m} . \mathrm{s}^{-2}$ is reached [2]. The test is assessed by determining the pressure in the brake pipe system in order to reach the brake deceleration of $5 \mathrm{~m} . \mathrm{s}^{-2}$ for the front axle brake and the deceleration of $3 \mathrm{~m} . \mathrm{s}^{-2}$ for the rear axle brake. The pressure is determined from the processed graphical dependence of the deceleration reached on the pressure in the system - Fig. 7. The found values for a spare brake lining must be within the range of $15 \%$ of deviations of the values for the original lining.

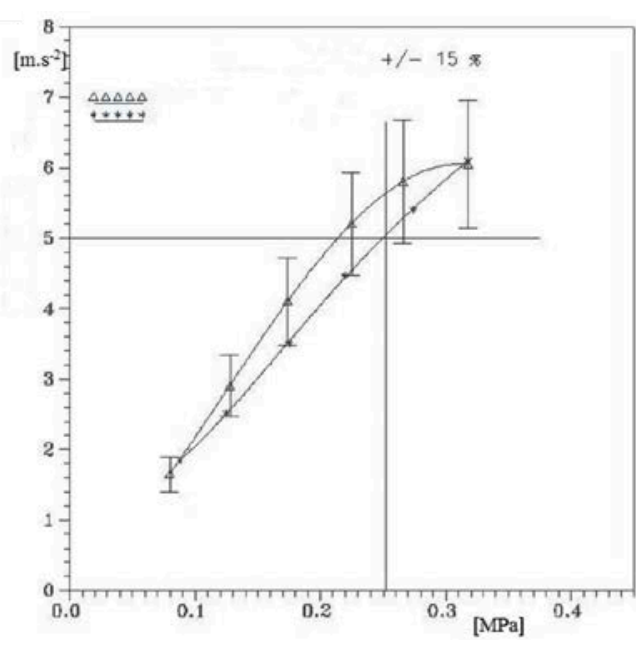

Fig.7. "Cold effect" test (braking deceleration in dependence on the pressure in the braking system for original $-\Delta$; for tested -* material) [1]

\subsection{Non-standard testing}

Insufficient assessment of the spare brake lining by means of authorized tests is illustrated on a concrete example. After the bus crash with tragic consequences (the main reason was insufficient braking effect at downhill drive) brake lining testing was performed:

- authorized tests (in compliance with standard R90.ECE) and,

- specific - with interrupted braking,

- with continuous braking.

Input parameters for testing: drum and shoes from the bus C734.40; tires $11.00 \mathrm{R} 22.5$; depth of lining BUS 13 mm; mass upon the front axle $10200 \mathrm{~kg}$; original lining COSID PA 320.

Results of official tests:

a) Cold effect - Table 1 . 
Table 1. Cold effect

\begin{tabular}{|c|c|c|c|c|c|}
\hline \multicolumn{2}{|c|}{ BUS } & \multicolumn{3}{c|}{ COSID } \\
\hline $\begin{array}{c}\text { Temperature } \\
{\left[{ }^{\circ} \mathrm{C}\right]}\end{array}$ & $\begin{array}{c}\text { Pressure } \\
{[\mathrm{MPa}]}\end{array}$ & $\begin{array}{c}\text { Deceleration } \\
{\left[\mathrm{m.s}^{-2}\right]}\end{array}$ & $\begin{array}{c}\text { Temperature } \\
{\left[{ }^{\circ} \mathrm{C}\right]}\end{array}$ & $\begin{array}{c}\text { Pressure } \\
{[\mathrm{MPa}]}\end{array}$ & $\begin{array}{c}\text { Deceleration } \\
{\left[\mathrm{m}^{-2} \mathbf{s}^{-2}\right]}\end{array}$ \\
\hline below 100 & 0.318 & 6.1 & below 100 & 0.318 & 6.05 \\
\hline below 100 & 0.274 & 5.4 & below 100 & 0.266 & 5.9 \\
\hline below 100 & 0.22 & 4.46 & below 100 & 0.22 & 5.2 \\
\hline below 100 & 0.175 & 3.5 & below 100 & 0.174 & 4.1 \\
\hline below 100 & 0.125 & 2.51 & below 100 & 0.128 & 3.0 \\
\hline below 100 & 0.088 & 1.84 & below 100 & 0.08 & 1.85 \\
\hline
\end{tabular}

Air pressure $0.252 \mathrm{MPa}$ in the braking system corresponds to deceleration $5 \mathrm{~m} . \mathrm{s}^{-2}$ for the used lining (BUS).

Characteristic: Cold effect - fulfilled.

b) Sensitivity to speed. Results are presented in Table 2.

Table 2. Sensitivity to speed BUS

\begin{tabular}{|c|c|c|c|c|}
\hline \multicolumn{5}{|c|}{ Initial speed $65 \mathrm{~km} \cdot \mathrm{h}^{-1}$} \\
\hline $\begin{array}{c}\text { Temperature } \\
{\left[{ }^{\circ} \mathrm{C}\right]}\end{array}$ & $\begin{array}{c}\text { Pressure } \\
\text { [MPa] }\end{array}$ & $\begin{array}{c}\text { Mean pressure } \\
{[\mathrm{MPa}]}\end{array}$ & $\begin{array}{c}\text { Deceleration } \\
{\left[\mathrm{m}^{\left.-\mathrm{s}^{-2}\right]}\right.}\end{array}$ & $\begin{array}{c}\text { Mean deceleration } \\
{\left[\mathrm{m}^{\left.-\mathrm{s}^{-2}\right]}\right.}\end{array}$ \\
\hline 73 & 0.253 & \multirow{3}{*}{0.252} & 5.28 & \multirow{3}{*}{5.22} \\
\hline 82 & 0.252 & & 5.22 & \\
\hline 93 & 0.251 & & 5.16 & \\
\hline \multicolumn{5}{|c|}{ Initial speed $100 \mathrm{~km} \cdot \mathrm{h}^{-1}$} \\
\hline $\begin{array}{c}\text { Temperature } \\
{\left[{ }^{\circ} \mathrm{C}\right]}\end{array}$ & $\begin{array}{c}\text { Pressure } \\
\text { [MPa] }\end{array}$ & $\begin{array}{c}\text { Mean pressure } \\
{[\mathrm{MPa}]}\end{array}$ & $\begin{array}{c}\text { Deceleration } \\
{\left[\mathrm{m}^{\left.-\mathrm{s}^{-2}\right]}\right.}\end{array}$ & $\begin{array}{c}\text { Mean deceleration } \\
{\left[\mathrm{m}_{\mathrm{s}} \mathrm{s}^{-2}\right]}\end{array}$ \\
\hline 95 & 0.254 & \multirow{3}{*}{0.251} & 4.62 & \multirow{3}{*}{4.66} \\
\hline 95 & 0.258 & & 4.6 & \\
\hline 94 & 0.252 & & 4.75 & \\
\hline
\end{tabular}

Sensitivity to speed for COSID

\begin{tabular}{|c|c|c|c|c|}
\hline \multicolumn{5}{|c|}{ Initial speed $65 \mathrm{~km} \cdot \mathrm{h}^{-1}$} \\
\hline $\begin{array}{c}\text { Temperature } \\
{\left[{ }^{\circ} \mathrm{C}\right]}\end{array}$ & $\begin{array}{c}\text { Pressure } \\
{[\mathrm{MPa}]}\end{array}$ & $\begin{array}{c}\text { Mean pressure } \\
{[\mathrm{MPa}]}\end{array}$ & $\begin{array}{c}\text { Deceleration } \\
{\left[\mathrm{m}^{\left.-\mathrm{s}^{-2}\right]}\right.}\end{array}$ & 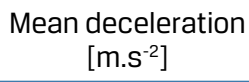 \\
\hline 64 & 0.199 & \multirow{3}{*}{0.199} & 4.75 & \multirow{3}{*}{4.9} \\
\hline 72 & 0.198 & & 4.85 & \\
\hline 80 & 0.199 & & 5.1 & \\
\hline
\end{tabular}




\begin{tabular}{|c|c|c|c|c|}
\hline \multicolumn{5}{|c|}{ Initial speed $100 \mathrm{~km} \cdot \mathrm{h}^{-1}$} \\
\hline $\begin{array}{c}\text { Temperature } \\
{\left[{ }^{\circ} \mathrm{C}\right]}\end{array}$ & $\begin{array}{c}\text { Pressure } \\
\text { [MPa] }\end{array}$ & $\begin{array}{c}\text { Mean pressure } \\
{[\mathrm{MPa}]}\end{array}$ & $\begin{array}{c}\text { Deceleration } \\
{\left[\mathrm{m} \cdot \mathrm{s}^{-2}\right]}\end{array}$ & 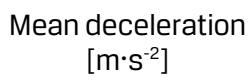 \\
\hline 82 & 0.199 & \multirow{3}{*}{0.199} & 4.65 & \multirow{3}{*}{4.7} \\
\hline 78 & 0.199 & & 4.75 & \\
\hline 74 & 0.199 & & 4.7 & \\
\hline
\end{tabular}

Characteristic: Sensitivity to speed fulfilled

c) Friction characteristics

The results for drum revolutions $305 \pm 51 \mathrm{~min}^{-1}$ and wheel diameter $1050 \mathrm{~mm}$ are presented in Table 3.

The mean braking moment is determined as an average of the highest and lowest moment values during the fifth braking in the first and fifth cycles. Hot braking moment is the least braking moment during the second and forth cycles of braking. Temperature did not exceed the value $300^{\circ} \mathrm{C}$.

The value of mean braking moment lies in 15\% tolerance field of lining COSID.

The value of hot braking moment of the lining BUS is greater than the one of the lining COSID.

Table 3. Friction characteristics

\begin{tabular}{|l|c|c|}
\hline & BUS & COSID \\
\hline Mean braking moment $\mathrm{M}_{\text {mean }}[\mathrm{N} . \mathrm{m}]$ & 2923 & 3308 \\
\hline Hot braking moment $\mathrm{M}_{\text {hot }}[\mathrm{N} . \mathrm{m}]$ & 2174 & 1997 \\
\hline
\end{tabular}

Characteristic: Friction characteristics - fulfilled

Specific tests

Untypical tests with interrupted braking were performed ( 21 times - 5 seconds braked and 11 second unbraked) for the constant speed $60 \mathrm{~km}$.hod ${ }^{-1}$ with cooling air supply. Pressure in the braking system was approx. $0.170 \mathrm{MPa}$. Test of this result is shown in Fig. 8 . In the diagram in Fig. 8 we can see decrease in the braking moment and increase in temperature of lining in time. Within $300 \mathrm{~s}$ the lining temperature taken in a measured point increased to approx. $450^{\circ} \mathrm{C}$. In the mentioned time the braking moment decreased by approx. 1000 N.m.

Next, uninterrupted braking was performed - "braking on the slope" to the constant speed $40 \mathrm{~km}$.hod-1, pressure in the system $0.170 \mathrm{MPa}$. Results are presented in Fig. 9. Within this testing a sharp decrease in the braking moment value was noticed (from the original 
value approx. $3000 \mathrm{Nm}$ to the value approx. $700 \mathrm{Nm}$ ) in the time of approx. 2 min from the start of braking. This decrease could be noticed when a certain temperature of brake lining (approx. $250^{\circ} \mathrm{C}$ ) is achieved. Simultaneously, dusting could be noticed - lining reduction.

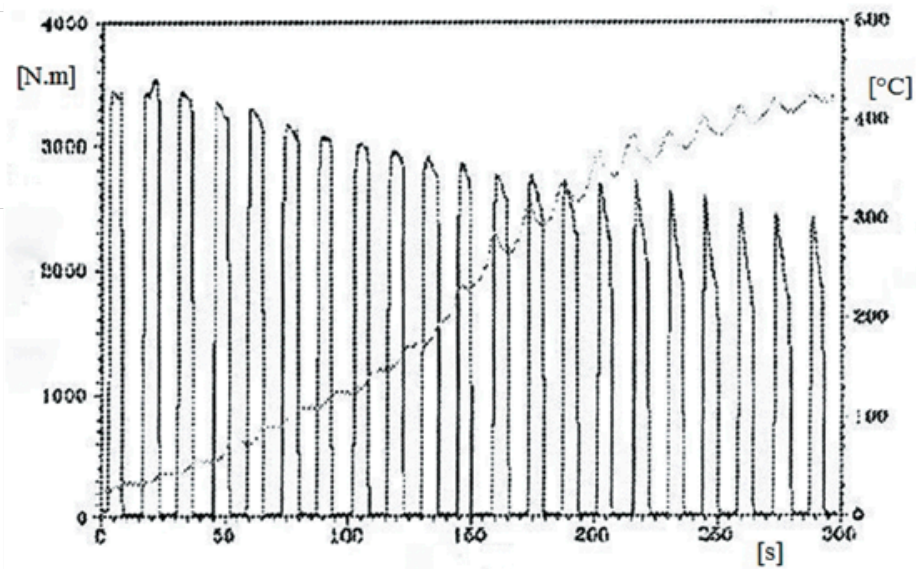

Fig. 8 Interrupted braking to constant speed (time dependence of braking moment and temperature of lining)

From the experimental testing it is obvious that the tested lining on the brake shoes of the crashed bus:

- $\quad$ met the requirements specified by the standard R90 ECE:

cold effect (at the boundary of fulfillment),

sensitivity to speed,

friction characteristics,

- in specific tests during interrupted braking at the speed $60 \mathrm{~km}$.hod ${ }^{-1}$ decrease of braking moment and more expressive increase of temperature approx. after $100 \mathrm{~s}$ were observed,

- in specific tests during uninterrupted braking at the speed $40 \mathrm{~km}^{-h^{-1}}$ sharp decrease of braking moment approx. after $100 \mathrm{~s}$ and increase in temperature were observed.

Figs. 8 and 9 offer the results of a non-standard test of an uninterrupted braking to the constant speed of $40 \mathrm{~km} \cdot \mathrm{h}^{-1}$, and of a test with interrupted braking to the constant speed of $60 \mathrm{~km} \cdot \mathrm{h}^{-1}$. At the testing of constant speed with uninterrupted braking a sharp decrease in the braking moment was noticed. At the testing with interrupted braking the decrease in the braking moment was much milder.

These two tests were performed on the brake lining of a crashed vehicle. In spite of the fact that the lining was satisfactory in standard tests, non-standard testing pointed to the cause of the vehicle crash - insufficient properties of the lining for braking during prolonged downhill drive. 


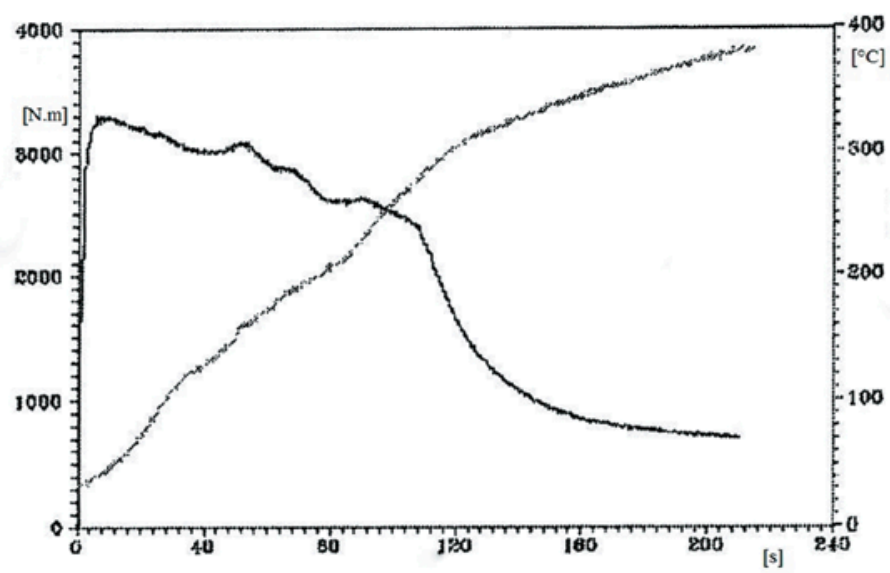

Fig.9. Uninterrupted braking to constant speed (time dependence of braking moment and temperature of lining)

\section{Conclusion}

The paper points out to some ways of investigating properties of materials for vehicle braking linings. It does not deal with mutual relations and correlation dependencies between the results gathered from experiments on the test stand and vehicle tests. In future it would be suitable to find possible relations between specific test results achieved on the braking test bench and results from vehicle testing, e.g. type I. The simulation of vehicle tests of type 0 is also possible at maintaining energy ratios. Such relations would be consequently used at traffic accident investigations when accidents were caused by brake lining.

\section{References}

[1] HLAVŇA, V. et al.: Tests of automobile brake linings; research reports for manufacturers of brake linings and lining materials (in Slovak).

[2] HLAVŇA, V., ŘEZNíČEK, R.: Niektoré problémy suchého trenia, EDIS vydavatel'stvo ŽU, 2002, ISBN 8071008850.

[3] KAMIŇSKI, Z:: Modelowanie charakterystyki siłowej bębnowych mechanizmów hamujących przyczep rolniczych, The Archives of Automotive Engineering - Archiwum Motoryzacji 1/2008, Wydawnictwo Naukowe PIMOT Warszawa ISSN: 1234-754X. 